\title{
Virtual Biopsy for Diagnosis of Chemotherapy-Associated Liver Injuries and Steatohepatitis: A Combined Radiomic and Clinical Model in Patients with Colorectal Liver Metastases
}

\author{
Guido Costa ${ }^{1,2,+}$, Lara Cavinato ${ }^{3,+}\left(\mathbb{D}\right.$, Chiara Masci $^{3}$, Francesco Fiz ${ }^{4}$, Martina Sollini ${ }^{2,4}$, \\ Letterio Salvatore Politi ${ }^{2,5}$, Arturo Chiti ${ }^{2,4}$, Luca Balzarini ${ }^{5}$, Alessio Aghemo ${ }^{2,6}$, Luca di Tommaso ${ }^{2,7}$, \\ Francesca Ieva ${ }^{3,8, *(\mathbb{D}}$, Guido Torzilli ${ }^{1,2}$ (D) and Luca Viganò $1,2, *$ (D)
}

1 Division of Hepatobiliary and General Surgery, Department of Surgery, IRCCS Humanitas Research Hospital, Rozzano, 20189 Milan, Italy; guido.costa@humanitas.it (G.C.); guido.torzilli@hunimed.eu (G.T.)

2 Department of Biomedical Sciences, Humanitas University, Pieve Emanuele, 20090 Milan, Italy; martina.sollini@hunimed.eu (M.S.); letterio.politi@hunimed.eu (L.S.P.); arturo.chiti@hunimed.eu (A.C.); alessio.aghemo@hunimed.eu (A.A.); luca.di_tommaso@hunimed.eu (L.d.T.)

3 MOX Laboratory, Department of Mathematics, Politecnico di Milano, 20133 Milan, Italy; lara.cavinato@polimi.it (L.C.); chiara.masci@polimi.it (C.M.)

4 Department of Nuclear Medicine, IRCCS Humanitas Research Hospital, 20189 Milan, Italy; francesco.fiz@cancercenter.humanitas.it

check for updates

Citation: Costa, G.; Cavinato, L.; Masci, C.; Fiz, F.; Sollini, M.; Politi, L.S.; Chiti, A.; Balzarini, L.; Aghemo, A.; di Tommaso, L.; et al. Virtual Biopsy for Diagnosis of Chemotherapy-Associated Liver Injuries and Steatohepatitis: A

Combined Radiomic and Clinical Model in Patients with Colorectal Liver Metastases. Cancers 2021, 13, 3077. https://doi.org/10.3390/ cancers13123077

Academic Editors: Enrico Cassano, Filippo Pesapane and Samuel C. Mok

Received: 15 March 2021

Accepted: 16 June 2021

Published: 20 June 2021

Publisher's Note: MDPI stays neutral with regard to jurisdictional claims in published maps and institutional affiliations.

Copyright: (c) 2021 by the authors. Licensee MDPI, Basel, Switzerland. This article is an open access article distributed under the terms and conditions of the Creative Commons Attribution (CC BY) license (https:// creativecommons.org/licenses/by/ $4.0 /)$.
5 Department of Radiology, IRCCS Humanitas Research Hospital, Rozzano, 20189 Milan, Italy; luca.balzarini@humanitas.it

6 Division of Internal Medicine and Hepatology, Department of Internal Medicine, IRCCS Humanitas Research Hospital, Rozzano, 20189 Milan, Italy

7 Pathology Unit, IRCCS Humanitas Research Hospital, 20189 Milan, Italy

8 CADS-Center for Analysis, Decisions and Society, Human Technopole, 20157 Milan, Italy

* Correspondence: francesca.ieva@polimi.it (F.I.); luca.vigano@hunimed.eu (L.V.)

+ These authors equally contributed to the manuscript.

Simple Summary: Patients receiving chemotherapy for liver metastases from colorectal cancer may develop liver injuries that impair hepatic function and postoperative outcome. The non-invasive diagnosis of these damages is still an unmet need. Recently, advanced imaging analysis techniques, including the so-called "radiomics", achieved adequate prediction of pathology data. The present study demonstrated that radiomic analysis of liver parenchyma in combination with clinical and laboratory data improves non-invasive diagnosis of chemotherapy-related liver injuries.

Abstract: Non-invasive diagnosis of chemotherapy-associated liver injuries (CALI) is still an unmet need. The present study aims to elucidate the contribution of radiomics to the diagnosis of sinusoidal dilatation (SinDil), nodular regenerative hyperplasia (NRH), and non-alcoholic steatohepatitis (NASH). Patients undergoing hepatectomy for colorectal metastases after chemotherapy (January 2018-February 2020) were retrospectively analyzed. Radiomic features were extracted from a standardized volume of non-tumoral liver parenchyma outlined in the portal phase of preoperative post-chemotherapy computed tomography. Seventy-eight patients were analyzed: 25 had grade 2-3 SinDil, $27 \mathrm{NRH}$, and $14 \mathrm{NASH}$. Three radiomic fingerprints independently predicted SinDil: GLRLM_f3 (OR = 12.25), NGLDM_f1 (OR = 7.77), and GLZLM_f2 (OR = 0.53). Combining clinical, laboratory, and radiomic data, the predictive model had accuracy $=82 \%$, sensitivity $=64 \%$, and specificity $=91 \%$ (AUC $=0.87$ vs. $A U C=0.77$ of the model without radiomics). Three radiomic parameters predicted NRH: conventional_HUQ2 (OR = 0.76), GLZLM_f2 (OR = 0.05), and GLZLM_f3 (OR = 7.97). The combined clinical/laboratory/radiomic model had accuracy $=85 \%$, sensitivity $=81 \%$, and specificity $=86 \%($ AUC $=0.91$ vs. AUC $=0.85$ without radiomics $)$. NASH was predicted by conventional_HUQ2 (OR $=0.79)$ with accuracy $=91 \%$, sensitivity $=86 \%$, and specificity $=92 \%$ (AUC $=0.93$ vs. AUC $=0.83$ without radiomics). In the validation set, accuracy was $72 \%, 71 \%$, and $91 \%$ for SinDil, NRH, and NASH. Radiomic analysis of liver parenchyma may provide a signature that, in combination with clinical and laboratory data, improves the diagnosis of CALI. 
Keywords: chemotherapy-associated liver injuries; sinusoidal dilatation; nodular regenerative hyperplasia; steatohepatitis; diagnostic imaging; radiomics; textural features; colorectal liver metastases; liver surgery; virtual liver biopsy

\section{Introduction}

The combination of chemotherapy and surgery is the standard treatment of patients with colorectal liver metastases (CLM) [1,2]. Systemic chemotherapy prolongs progressionfree survival, allows for the selection of the candidates for surgery, and moves some initially unresectable patients to secondary resectability [3-7]. However, systemic treatment may lead to chemotherapy-associated liver injuries (CALI) such as sinusoidal dilatation, nodular regenerative hyperplasia (NRH), and non-alcoholic steatohepatitis (NASH) [8-11]. Generally, sinusoidal dilatation and NRH are related to oxaliplatin-based chemotherapy $[8,10,12]$, while steatohepatitis is associated with irinotecan-based chemotherapy $[9,13]$. Steatohepatitis can be caused not only by chemotherapy, but also observed in patients with metabolic disorders $[14,15]$. This is epidemiologically relevant given the increasing prevalence of such disorders in the general population. CALI are of major interest for liver surgeons because of their association with an increased risk of intraoperative bleeding, postoperative morbidity, and liver dysfunction [9,10,16-20].

Preoperative diagnosis of CALI is still an unmet need [21]. Presently, the prediction of CALI relies on risk factors (e.g., chemotherapy regimen and duration) [9-11,16], some laboratory tests and scores (e.g., APRI score, ICG tests, and LiMax test) $[10,16,19,22-24]$ and imaging modalities (e.g., heterogeneous liver parenchyma at computed tomography (CT) and magnetic resonance imaging) [25,26], but has limited accuracy. Also liver biopsy has low effectiveness because of the heterogeneous distribution of injuries and insufficient sample size [27].

In the last few years, a new approach to medical imaging has gained momentum. It is driven by the hypothesis that tissue features could be expressed on the radiological images as voxel patterns, which are invisible to the human eye. To identify these patterns, mathematical functions analyzing the spatial relation and the frequency distribution of gray levels in the voxels were developed, providing modern and specific image biomarkers $[28,29]$. This texture-based approach has been termed "radiomics". However, although texture analysis has shown high accuracy in the identification of liver fibrosis [30-33], no studies have yet focused on radiomics for CALI.

The present analysis aims to investigate whether the radiomic features extracted from preoperative CT imaging can improve diagnosis of NASH and CALI in patients undergoing liver resection for CLM after preoperative chemotherapy. A defined volume of non-tumoral liver parenchyma was analyzed, thus performing a "virtual biopsy".

\section{Material and Methods}

All consecutive patients that underwent liver resection for CLM between January 2018 and February 2020 were retrospectively considered. The following inclusion criteria were adopted: preoperative chemotherapy for at least two months; oxaliplatin- or irinotecanbased chemotherapy regimen; availability of preoperative CT for imaging review and texture analysis; preoperative imaging performed $<2$ months before liver resection.

The primary endpoint of the study was to analyze the contribution of radiomic analysis of liver parenchyma in the portal phase of preoperative post-chemotherapy CT scan to the diagnosis of clinically relevant CALI. Clinically relevant CALI included grade 2-3 sinusoidal dilatation, NRH of any grade, and NASH. Radiomic features were extracted from a standardized volume of interest (VOI) of non-tumoral liver parenchyma identified on the portal phase of the CT scan. The VOI was a cylinder with a basis diameter of $10 \mathrm{~mm}$ and a height of $25 \mathrm{~mm}$ outlined in the right liver between the anterior and posterior sections and positioned not to include CLM or major intrahepatic vessels. If an adequate VOI of 
non-tumoral parenchyma was not available in the right liver, the VOI was outlined in the left liver. In any case, a minimal distance of $20 \mathrm{~mm}$ between the VOI and CLM was respected. In all patients, VOI had the same shape, dimension, and requisites (no major vessels and no CLM). Radiomic features were automatically extracted from the VOI by the LifeX @software 6 [34,35]. The study was approved by the local ethics committee and, because of its retrospective design, the need for informed consent was waived.

\subsection{Patients Management and Pathology Data}

The management of patients with CLM candidates to liver resection has been previously reported [36-38]. After the end of chemotherapy, patients were considered for surgery only in case of stable disease or partial response to treatment. Liver resection was performed 4 to 6 weeks after the end of chemotherapy (six weeks if bevacizumab was administered).

In the authors' institution, CALI are prospectively assessed in all patients undergoing resection for CLM after preoperative chemotherapy. For the present study, all specimens were reviewed by a single expert pathologist (L.d.T.). The sample of non-tumoral hepatic parenchyma was taken at a distance of at least $10 \mathrm{~mm}(20 \mathrm{~mm}$ whenever possible) from the tumor and the resection margin [39]. The tissue specimen (minimum area $1 \mathrm{~cm}^{2}$ ) was fixed in formalin, paraffin-embedded, and stained with hematoxylin-eosin, Masson's trichrome, and Gomori staining. CALI evaluation was performed according to standard criteria. In details, sinusoidal dilatation was graded semi-quantitatively (from grade 0 to grade 3 ), according to Rubbia-Brandt et al. [8]; NRH was graded (from grade 0 to grade 3 ) according to the Wanless scoring system [40]; and NASH definition was based on Kleiner et al., adopting the cut-off value modified by Vauthey et al. and the scoring system of the most recent guidelines (steatohepatitis defined as the joint presence of steatosis, ballooning, and lobular inflammation ) [9,41,42] (Table S1). Fibrosis was assessed according to the METAVIR score [43].

\subsection{Statistical Analyses}

Summary statistics were constructed with the use of frequencies and proportions for categorical data and medians and ranges for continuous variables. Chi-square (or Fisher's exact test) and t-test (or Mann-Whitney $U$ test) were used to evaluate potential differences in the distribution of variables according to different CALI. Univariate analysis was carried out to explore the association between the different CALI and clinical (i.e., dyslipidemia, diabetes, metabolic syndrome, body mass index (BMI), type and length of chemotherapy, age), laboratory variables (i.e., APRI, GGT), and chemotherapy details.

A multivariate logistic regression model was performed to estimate the adjusted association between each candidate predictor and the presence of different CALI (grade 2-3 sinusoidal dilatation, $\mathrm{NRH}$, or steatohepatitis). Clinical rationale associated with a backward stepwise regression approach was used to retain only relevant associations. In particular: a principal component analysis (PCA) of second-order radiomic features, i.e., textural features quantifying tumor heterogeneity by analyzing the spatial distribution of pixel/voxel intensities, was performed to obtain effective predictors (Fingerprint in the following) for the model. PCA was performed on the following matrices: gray-level co-occurrence matrices (GLCM), gray-level run-length matrices (GLRLM), neighboring gray-level difference matrices (NGLDM), and gray-level zone-length matrices (GLZLM). For each of them, we retained components of the PCA that explain at least $95 \%$ of original features variability. Note that the retained fingerprints have neither clinical nor biological interpretations, but related estimates (OR and CI) may be interpreted as usual. Clinical and laboratory variables were selected according to $a$ priori knowledge and the results of univariate analysis; then a stepwise regression was run, and all the variables retained by this procedure were used for predictive purposes. Continuous variables were included as continuous predictors, i.e., without assuming any categorization with arbitrary thresholds. Finally, a correlation matrix of continuous variables and correlation heat-map were gen- 
erated. Correlation between features was analyzed and, whenever higher than 0.85 , one of the two features involved in the correlation was removed. The final predictive model underwent internal cross-validation by splitting the series into a training set (90\% of the population) and a validation set (10\%). The validation procedure was repeated 100 times over 100 different samples. Results are reported in terms of mean (Std Dev) accuracy.

A decision tree was built with the variables retained by the backward stepwise selection of the multivariate model to highlight and exploit the possible nonlinear association with the outcome. Indeed, a decision tree for classification problems is a top-down greedy algorithm that divides the predictor space into distinct and non-overlapping regions (identified by the criteria/split adopted to reach each node). The slitting criteria for decision rules are defined according to the principle of minimizing the variability of the response within each node. For every observation falling into one region (node), the decision tree predicts the occurrence of the corresponding CALI of interest. Decision trees are displayed as dendrograms to highlight decision steps. Each node of the tree reports: (a) the response mode class in the node, i.e., the predicted outcome for that node (presence of CALI $=1$; absence of CALI = 0, the top number in the square); (b) the percentages of observations in the node belonging to the first response class (absence of CALI) and the second response class (presence of CALI) (the two central numbers in the square, summing up to 1); (c) the percentage of the total population falling into the node (the bottom number in the square). Decision rules are specified on each split.

Stata 15 [44] and R software 1.2 [45] were used for all the analyses.

\section{Results}

In the study period (January 2018-February 2020), 78 consecutive patients that underwent liver resection for CLM after preoperative chemotherapy were enrolled in the present study. Of these, $47(60 \%)$ patients were male, and the median age of the entire cohort was 65 (range $30-82$ ) years. Eleven (14\%) patients were obese (BMI > $\left.30 \mathrm{~kg} / \mathrm{m}^{2}\right), 8(10 \%)$ had a metabolic syndrome, and two (3\%) had chronic medications potentially associated with NASH [46] (steroids in one, and tamoxifen in one). No patient had chronic medication potentially associated with NRH or sinusoidal dilatation $[47,48]$. CLMs were synchronous with the primary tumor in $54(70 \%)$ patients, multiple in $70(90 \%)$, and larger than $50 \mathrm{~mm}$ in $13(17 \%)$. All patients had oxaliplatin- or irinotecan-based preoperative chemotherapy. Targeted therapies were associated with chemotherapy in $65(83 \%)$ patients, anti-VEGF being the commonest one $(58 \%, n=45)$. Table 1 summarizes chemotherapy details. The median interval between chemotherapy and liver surgery was five weeks (range 4-7). All patients but four underwent minor hepatectomy. No patient had preoperative or intraoperative signs of portal hypertension. Ninety-day operative mortality rate was nil, five (6\%) patients had postoperative severe morbidity and two (3\%) had grade B-C liver failure.

Table 1. Details of chemotherapy and pathology data.

\begin{tabular}{cc}
\hline \multicolumn{2}{c}{ Chemotherapy Data } \\
\hline Regimen \\
\hline Oxaliplatin \\
\hline Irinotecan & $69(88 \%)$ \\
\hline Anti-VEGF treatment & $33(42 \%)$ \\
\hline Anti-EGFR treatment & $45(58 \%)$ \\
\hline Number of cycles, median (range) & $29(37 \%)$ \\
\hline$>6$ cycles & $8(3-35)$ \\
\hline$\geq 2$ lines & $48(62 \%)$ \\
\hline Interval chemotherapy-surgery, weeks, median (range) & $25(32 \%)$ \\
\hline
\end{tabular}


Table 1. Cont.

\begin{tabular}{cc}
\hline \multicolumn{1}{c}{ Chemotherapy Data } \\
\hline CALI \\
\hline Sinusoidal dilatation \\
\hline Grade 2-3 ${ }^{*}$ & $56(72 \%)$ \\
\hline NRH & $25(32 \%)$ \\
\hline Grade 2-3 ${ }^{* *}$ & $27(35 \%)$ \\
\hline Steatosis & $9(12 \%)$ \\
\hline Grade 2-3 $* * *$ & $34(44 \%)$ \\
\hline Lobular inflammation & $19(24 \%)$ \\
\hline Hepatocellular ballooning & $21(27 \%)$ \\
\hline NASH $* * *$ & $14(18 \%)$ \\
\hline
\end{tabular}

VEGF, Vascular Endothelial Growth Factor; EGFR, Epidermal Growth Factor Receptor; CALI, ChemotherapyAssociated Liver Injury; NRH, Nodular Regenerative Hyperplasia; NASH, Non-alcoholic Steatohepatitis; * according to Rubbia-Brandt et al. [8]; ** according to the Wanless scoring system [40]; ${ }^{* *}$ according to Kleiner et al. [41] $* * * *$ according to EASL guidelines, Marchesini et al. [42].

At the final pathology examination, CALI were evident in 61 (78\%) patients (Table 1). In details, grade $2-3$ sinusoidal dilatation was present in 25 (32\%) patients, NRH in 27 $(35 \%)$, and NASH in $14(18 \%)$. The association between CALI and patients' characteristics, laboratory data, and chemotherapy details is reported in Table 2.

Table 2. Association between CALI and clinical and laboratory data.

\begin{tabular}{|c|c|c|c|c|}
\hline \multicolumn{5}{|c|}{ Grade 2-3 Sinusoidal Dilatation } \\
\hline & & $\mathbf{N}$ & $\mathbf{Y}$ & $p$ \\
\hline Age, years, median (range) & & $61(30-82)$ & $66(51-80)$ & 0.032 \\
\hline APRI score, median (range) & & $0.33(0.10-1.16)$ & $0.50(0.12-1.89)$ & 0.006 \\
\hline GGT, UI/L, median (range) & & $59(7-247)$ & $76(11-372)$ & 0.290 \\
\hline BMI, kg/m², median (range) & & $25.8(19.0-40.3)$ & $24.9(20.4-33.6)$ & 0.368 \\
\hline \multirow{2}{*}{ Dyslipidemia } & $\mathrm{N}$ & $24(69 \%)$ & $11(31 \%)$ & \multirow{2}{*}{0.915} \\
\hline & $\mathrm{Y}$ & $29(67 \%)$ & $14(33 \%)$ & \\
\hline \multirow{2}{*}{ Diabetes } & $\mathrm{N}$ & $44(66 \%)$ & $23(34 \%)$ & \multirow{2}{*}{0.487} \\
\hline & $\mathrm{Y}$ & $9(82 \%)$ & $2(18 \%)$ & \\
\hline \multirow{2}{*}{ Metabolic syndrome } & $\mathrm{N}$ & $47(67 \%)$ & $23(33 \%)$ & \multirow{2}{*}{0.652} \\
\hline & $\mathrm{Y}$ & $6(75 \%)$ & $2(25 \%)$ & \\
\hline \multirow{2}{*}{ Oxaliplatin-based chemotherapy } & $\mathrm{N}$ & $7(78 \%)$ & $2(22 \%)$ & \multirow{2}{*}{0.502} \\
\hline & $\mathrm{Y}$ & $46(67 \%)$ & $23(33 \%)$ & \\
\hline \multirow{2}{*}{ Irinotecan-based chemotherapy } & $\mathrm{N}$ & $30(67 \%)$ & $15(33 \%)$ & \multirow{2}{*}{0.777} \\
\hline & $\mathrm{Y}$ & $23(70 \%)$ & $10(30 \%)$ & \\
\hline \multirow{2}{*}{ Anti-VEGF treatment } & $\mathrm{N}$ & $18(55 \%)$ & $15(45 \%)$ & \multirow{2}{*}{0.030} \\
\hline & $\mathrm{Y}$ & $35(78 \%)$ & $25(32 \%)$ & \\
\hline \multirow{2}{*}{ Number of cycles of chemotherapy } & $1-6$ & $19(63 \%)$ & $11(37 \%)$ & \multirow{2}{*}{0.490} \\
\hline & $>6$ & $34(71 \%)$ & $14(29 \%)$ & \\
\hline
\end{tabular}


Table 2. Cont.

\begin{tabular}{|c|c|c|c|c|}
\hline \multicolumn{5}{|c|}{ NRH } \\
\hline & & $\mathbf{N}$ & $\mathbf{Y}$ & $p$ \\
\hline Age, years, median (range) & & $62(30-82)$ & $64(47-80)$ & 0.333 \\
\hline APRI score, median (range) & & $0.32(0.10-1.16)$ & $0.49(0.12-1.89)$ & 0.006 \\
\hline GGT, UI/L, median (range) & & $54(7-247)$ & $83(11-372)$ & 0.032 \\
\hline BMI, $\mathrm{kg} / \mathrm{m}^{2}$, median (range) & & $26.0(19.0-40.3)$ & $4.6(20.4-32.3)$ & 0.161 \\
\hline \multirow{2}{*}{ Dyslipidemia } & $\mathrm{N}$ & $21(60 \%)$ & $14(40 \%)$ & \multirow{2}{*}{0.367} \\
\hline & $\mathrm{Y}$ & $30(70 \%)$ & $13(30 \%)$ & \\
\hline \multirow{2}{*}{ Diabetes } & $\mathrm{N}$ & $43(64 \%)$ & $24(36 \%)$ & \multirow{2}{*}{0.739} \\
\hline & $\mathrm{Y}$ & $8(73 \%)$ & $3(27 \%)$ & \\
\hline \multirow{2}{*}{ Metabolic syndrome } & $\mathrm{N}$ & $44(63 \%)$ & $26(37 \%)$ & \multirow{2}{*}{0.165} \\
\hline & $\mathrm{Y}$ & $7(87 \%)$ & $1(13 \%)$ & \\
\hline \multirow{2}{*}{ Oxaliplatin-based chemotherapy } & $\mathrm{N}$ & $7(78 \%)$ & $2(22 \%)$ & \multirow{2}{*}{0.406} \\
\hline & $\mathrm{Y}$ & $44(64 \%)$ & $25(36 \%)$ & \\
\hline \multirow{2}{*}{ Irinotecan-based chemotherapy } & $\mathrm{N}$ & $31(69 \%)$ & $14(31 \%)$ & \multirow{2}{*}{0.447} \\
\hline & $\mathrm{Y}$ & $20(61 \%)$ & $13(39 \%)$ & \\
\hline \multirow{2}{*}{ Anti-VEGF treatment } & $\mathrm{N}$ & $17(52 \%)$ & $16(48 \%)$ & \multirow{2}{*}{0.027} \\
\hline & $\mathrm{Y}$ & $34(76 \%)$ & $11(24 \%)$ & \\
\hline \multirow{2}{*}{ Number of cycles of chemotherapy } & $1-6$ & $21(70)$ & $9(30 \%)$ & \multirow{2}{*}{0.498} \\
\hline & $>6$ & $30(62 \%)$ & $18(38 \%)$ & \\
\hline \multicolumn{5}{|c|}{ Steatohepatitis } \\
\hline & & $\mathbf{N}$ & $\mathbf{Y}$ & $p$ \\
\hline Age, years, median (range) & & $63(30-82)$ & $61(47-78)$ & 0.595 \\
\hline APRI score, median (range) & & $0.37(0.10-1.89)$ & $0.42(0.14-1.16)$ & 0.610 \\
\hline GGT, UI/L, median (range) & & $63(7-372)$ & $72(21-218)$ & 0.651 \\
\hline BMI, $\mathrm{kg} / \mathrm{m}^{2}$, median (range) & & $25.4(19.0-33.7)$ & $29.9(22.6-40.3)$ & $<0.001$ \\
\hline \multirow{2}{*}{ Dyslipidemia } & $\mathrm{N}$ & $31(89 \%)$ & $4(11 \%)$ & \multirow{2}{*}{0.239} \\
\hline & Y & $33(77 \%)$ & $10(23 \%)$ & \\
\hline \multirow{2}{*}{ Diabetes } & $\mathrm{N}$ & $55(82 \%)$ & $12(18 \%)$ & \multirow{2}{*}{1.000} \\
\hline & $\mathrm{Y}$ & $9(82 \%)$ & $2(18 \%)$ & \\
\hline \multirow{2}{*}{ Metabolic syndrome } & $\mathrm{N}$ & $60(86 \%)$ & $10(14 \%)$ & \multirow{2}{*}{0.013} \\
\hline & $\mathrm{Y}$ & $4(50 \%)$ & $4(50 \%)$ & \\
\hline \multirow{2}{*}{ Oxaliplatin-based chemotherapy } & $\mathrm{N}$ & $7(78 \%)$ & $2(22 \%)$ & \multirow{2}{*}{0.722} \\
\hline & $\mathrm{Y}$ & $57(83 \%)$ & $12(17 \%)$ & \\
\hline \multirow{2}{*}{ Irinotecan-based chemotherapy } & $\mathrm{N}$ & $40(89 \%)$ & $5(11 \%)$ & \multirow{2}{*}{0.066} \\
\hline & Y & $24(73 \%)$ & $9(27 \%)$ & \\
\hline \multirow{2}{*}{ Anti-VEGF treatment } & $\mathrm{N}$ & $31(94 \%)$ & $2(6 \%)$ & 0.019 \\
\hline & $\mathrm{Y}$ & $33(73 \%)$ & $12(27 \%)$ & \\
\hline Number of cycles of chemotherapy & $1-6$ & $25(83 \%)$ & $5(17 \%)$ & 0.816 \\
\hline & $>6$ & $39(81 \%)$ & $9(19 \%)$ & \\
\hline
\end{tabular}

APRI, AST-to-Platelet Ratio Index; GGT, Gamma-glutamyltransferase; BMI, Body Mass Index; VEGF, Vascular Endotelial Growth Factor; NRH, Nodular Regenerative Hyperplasia; N refers to NO; Y refers to YES. 
At the univariate analysis, grade $2-3$ sinusoidal dilatation and $\mathrm{NRH}$ were associated with preoperative APRI score (median value 0.50 if grade 2-3 sinusoidal dilatation vs. 0.33 if grade $0-1, p=0.006 ; 0.49$ if NRH vs. 0.32 if not, $p=0.006$ ) and were reduced in patients having received preoperative anti-VEGF therapy (32\% vs. $45 \%, p=0.030$, and $24 \%$ vs. $48 \%$, $p=0.027$, respectively). Steatohepatitis was associated with body mass index (BMI, median value $29.9 \mathrm{~kg} / \mathrm{m}^{2}$ if steatohepatitis vs. $25.4 \mathrm{~kg} / \mathrm{m}^{2}$ if not, $p<0.001$ ) and metabolic syndrome (50\% vs. $14 \%, p=0.013$, respectively). Of the patients with chronic medications potentially associated with NASH [46], none had steatohepatitis at the final pathology evaluation. The association between postoperative outcome and CALI is reported in Table S2. Of note, in the present series, three patients had F3 fibrosis; none had cirrhosis (F4).

The a priori defined characteristics of the VOI (dimension, shape, and distance from vessels and metastases) were respected in all cases. The VOIs were adequate and homogeneous in all patients.

\subsection{Predictive Model for Sinusoidal Dilatation}

At the multivariate analysis, the following clinical and laboratory variables were associated with grade $2-3$ sinusoidal dilatation (Table 3): age (Odds Ratio (OR) = 1.11, Confidence Interval (CI)95\% $=1.02-1.21, p=0.015)$, anti-VEGF therapy associated with chemotherapy $(\mathrm{OR}=0.18, \mathrm{CI} 95 \%=0.04-0.77, p=0.021)$, and APRI score $(\mathrm{OR}=64.16$, $\mathrm{CI} 95 \%=3.32-120.3, p=0.006)$. In addition, three fingerprints derived from radiomic features were independent predictors of sinusoidal dilatation: GLRLM_f3 (OR = 12.25, CI95\% $=1.34-111.9, p=0.026)$, NGLDM_f1 (OR $=7.77$, CI95\% $=1.37-44.06, p=0.021)$, GLZLM_f2 (OR $=0.53$, CI95\% $=0.31-0.91, p=0.022)$.

Table 3. Multivariate analysis of predictors of grade 2-3 sinusoidal dilatation.

\begin{tabular}{ccc}
\hline Variable. & OR (95\% IC) & $p$ \\
\hline Age & $1.11(1.02-1.21)$ & 0.015 \\
\hline APRI score & $64.16(3.32-120.30)$ & 0.006 \\
\hline Oxaliplatin-based chemotherapy & $11.92(0.54-26.29)$ & 0.118 \\
\hline Irinotecan-based chemotherapy & $3.46(0.66-18.18)$ & 0.142 \\
\hline Anti-VEGF treatment & $0.18(0.04-0.77)$ & 0.021 \\
\hline Number of cycles of chemotherapy & $1.08(0.98-1.2)$ & 0.128 \\
\hline Hist_IQR & $0.74(0.49-1.11)$ & 0.144 \\
\hline GLRLM_f3 & $12.25(1.34-111.90)$ & 0.026 \\
\hline NGLDM_f1 & $7.77(1.37-44.06)$ & 0.021 \\
\hline NGLDM_f2 & $0.28(0.04-1.73)$ & 0.169 \\
\hline GLZLM_f2 & $0.53(0.31-0.91)$ & 0.022 \\
\hline GLZLM_f4 & $1.72(0.85-3.48)$ & 0.131 \\
\hline
\end{tabular}

APRI, AST-to-Platelet Ratio Index; VEGF, Vascular Endothelial Growth Factor; Hist_IQR, Histogram Interquartile Range; GLRLM_f3, Grey-Level Run Length Matrix Fingerprint 3; NGLDM_f1, Neighborhood Grey-Level Different Matrix Fingerprint 1; NGLDM_f2, Neighborhood Grey-Level Different Matrix Fingerprint 2; GLZLM_f2, GreyLevel Zone Length Matrix Fingerprint 2; GLZLM_f4, Grey-Level Zone Length Matrix Fingerprint 4.

The combined clinical, laboratory and radiomic model had $82 \%$ accuracy, $64 \%$ sensitivity, and 91\% specificity (AUC = 0.87, Figure 1 ).

The model without radiomic features had AUC $=0.77$ (Figure S1, delta AUC with the model including the radiomic features $=-0.10)$. We built a decision tree based on the results of multivariate analysis (Figure 2 ). 


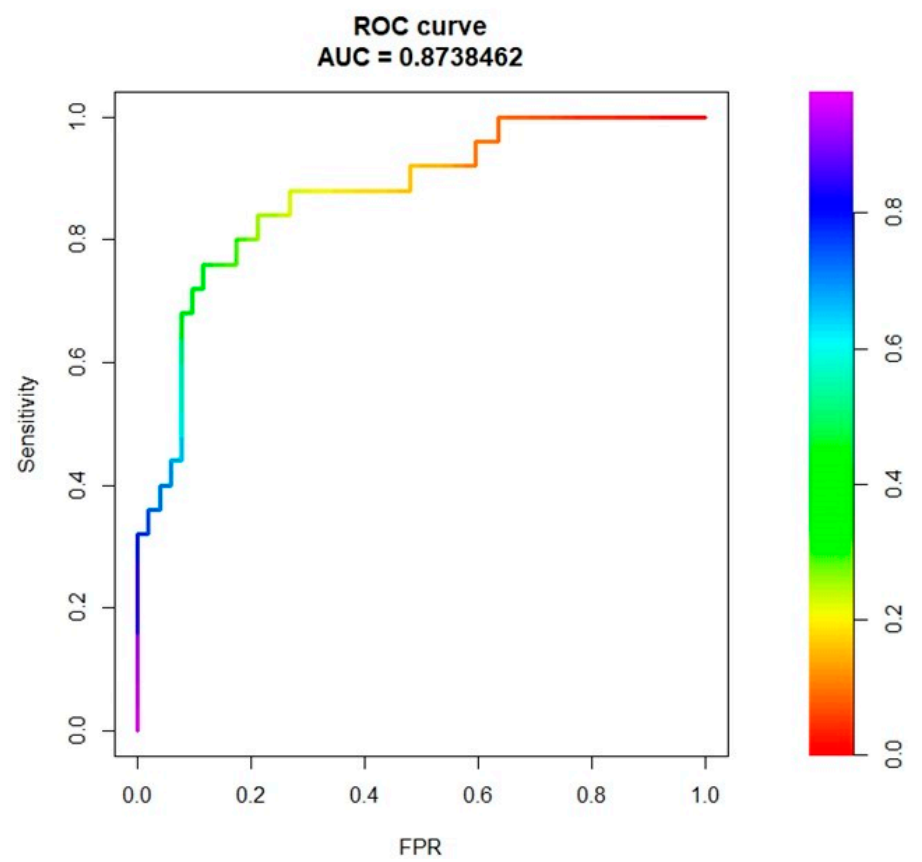

Figure 1. ROC curve analysis referring to the prediction of sinusoidal dilatation (grade $0-1$ vs. grade 2-3), considering clinical, laboratory, and radiomic variables for model training.

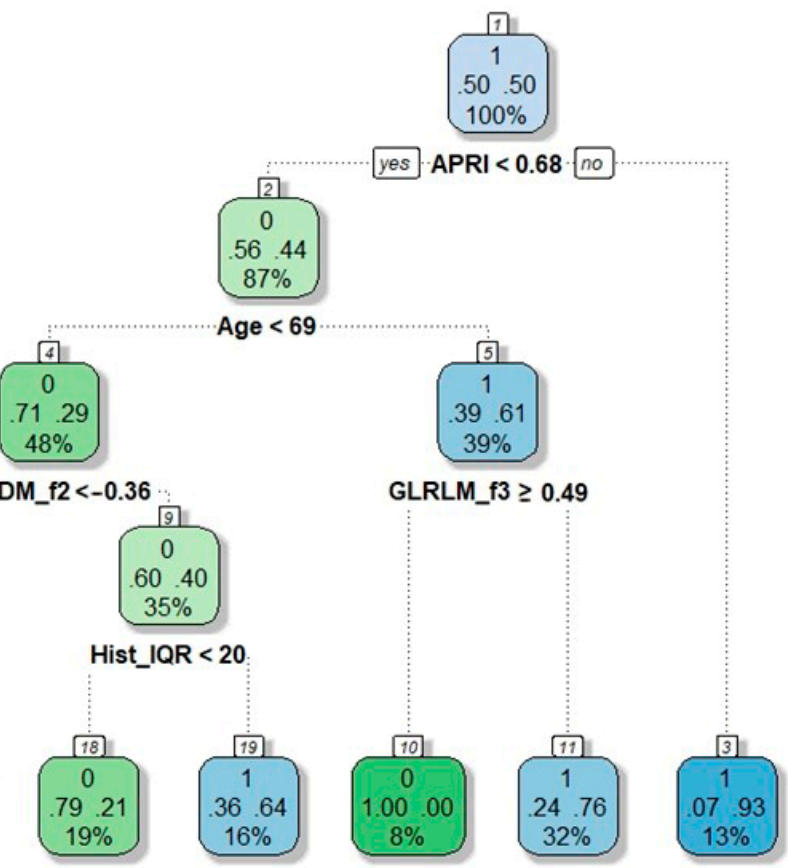

Figure 2. Decision tree for the prediction of grade $0-1$ vs. grade $2-3$ sinusoidal dilatation (based on model in Table 3). Nodes correspond to the decision steps. Each colored square reports: (a) the response mode class in the node, i.e., the predicted outcome of that node (presence of grade 2-3 sinusoidal dilatation $=1$; absence of grade $2-3$ sinusoidal dilatation $=0$, the top number in the square); (b) the percentages of observations in the node belonging to the first response class (absence of grade 2-3 sinusoidal dilatation) and the second response class (presence of grade 2-3 sinusoidal dilatation) (the two central numbers in the square, summing up to 1); (c) the percentage of the total population falling into the node (the bottom number in the square). Decision rules are specified on each node. 
The following knots were identified: age $<69$ years, APRI score $<0.68$, NGLDM_f2 < -0.36 , Hist_IQR $<20$, GLRLM_f3 $\geq 0.49$. The decision tree achieved $78 \%$ accuracy, $92 \%$ sensitivity, and $72 \%$ specificity (AUC $=0.87$ ).

In the validation set, the multivariate logistic regression had an average accuracy of $72 \%$ (Std Dev 15\%).

\subsection{Predictive Model for NRH}

At the multivariate analysis, the following clinical and laboratory variables were associated with NRH (Table 4): age (OR $=1.10, \mathrm{CI} 95 \%=1.01-1.20, p=0.027), \mathrm{BMI}(\mathrm{OR}=0.68$, $\mathrm{CI95} \%=0.49-0.94, p=0.021)$, Irinotecan $(\mathrm{OR}=28.71, \mathrm{CI} 95 \%=1.8-459.04, p=0.018)$, number of cycles of chemotherapy $(\mathrm{OR}=1.15, \mathrm{CI} 95 \%=1.01-1.32, p=0.031)$, anti-VEGF therapy associated with chemotherapy $(\mathrm{OR}=0.05, \mathrm{CI} 95 \%=0.01-0.49, p=0.010)$, and APRI score $(\mathrm{OR}=275.08, \mathrm{CI} 95 \%=4.75-15937.97, p=0.007)$. In addition, three radiomic predictors of NRH were identified: conventional_HUQ2 (OR $=0.76$, CI95\% $=0.62-0.92$, $p=0.005)$, GLZLM_f2 (OR $=0.05$, CI95 $\%=0.01-0.43, p=0.007)$, and GLZLM_f3 (OR = 7.97, $\mathrm{CI} 95 \%=1.52-41.85, p=0.014)$.

Table 4. Multivariate analysis of predictors of NRH.

\begin{tabular}{ccc}
\hline Variable & OR (95\% IC) & $p$ \\
\hline Age & $1.10(1.01-1.20)$ & 0.027 \\
\hline APRI score & $275.08(4.75-15937.97)$ & 0.007 \\
\hline BMI & $0.68(0.49-0.94)$ & 0.021 \\
\hline Oxaliplatin-based chemotherapy & $34.41(0.52-2295.05)$ & 0.099 \\
\hline Irinotecan-based chemotherapy & $28.71(1.80-459.04)$ & 0.018 \\
\hline Anti-VEGF treatment & $0.05(0.01-0.49)$ & 0.010 \\
\hline Number of cycles of chemotherapy & $1.15(1.01-1.32)$ & 0.031 \\
\hline CONVENTIONAL_HUQ2 & $0.76(0.62-0.92)$ & 0.005 \\
\hline GLCM_f2 & $1.99(0.84-4.71)$ & 0.119 \\
\hline GLRLM_f3 & $0.39(0.11-1.42)$ & 0.153 \\
\hline NGLDM_f2 & $2.65(0.86-8.24)$ & 0.091 \\
\hline GLZLM_f2 & $0.05(0.01-0.43)$ & 0.007 \\
\hline GLZLM_f3 & $7.97(1.52-41.85)$ & 0.014 \\
\hline
\end{tabular}

APRI, AST-to-Platelet Ratio Index; BMI, Body Mass Index; VEGF, Vascular Endothelial Growth Factor; HUQ2, Hounsfield Unit Quartile 2; GLCM_f2, Gray - Level Co-occurrence Matrix Fingerprint 2; GLRLM_f3, Grey-Level Run Length Matrix Fingerprint 3; NGLDM_f2, Neighborhood Grey-Level Different Matrix Fingerprint 2; GLZLM_f2, Grey-Level Zone Length Matrix Fingerprint 2; GLZLM_f3, Grey-Level Zone Length Matrix Fingerprint 3.

The combined clinical, laboratory and radiomic model had $85 \%$ accuracy, $81 \%$ sensitivity, and $86 \%$ specificity (AUC $=0.91$, Figure 3 ). The model without radiomic features had AUC $=0.85$ (Figure S2, delta with the model including the radiomic features $=-0.06$ ). The decision tree based on the results of multivariate logistic regression had the following knots: APRI score < 0.28, BMI $\geq 24$, GLZLM_f3 < -0.3, GLZLM_f3 $\leq$ 0.5, GLCM_f2 < 0.094 (Figure 4 ). It achieved $83 \%$ accuracy, $89 \%$ sensitivity, and $80 \%$ specificity (AUC $=0.88$ ).

In the validation set, the multivariate logistic regression had an average accuracy of 71\% (Std Dev 12\%). 


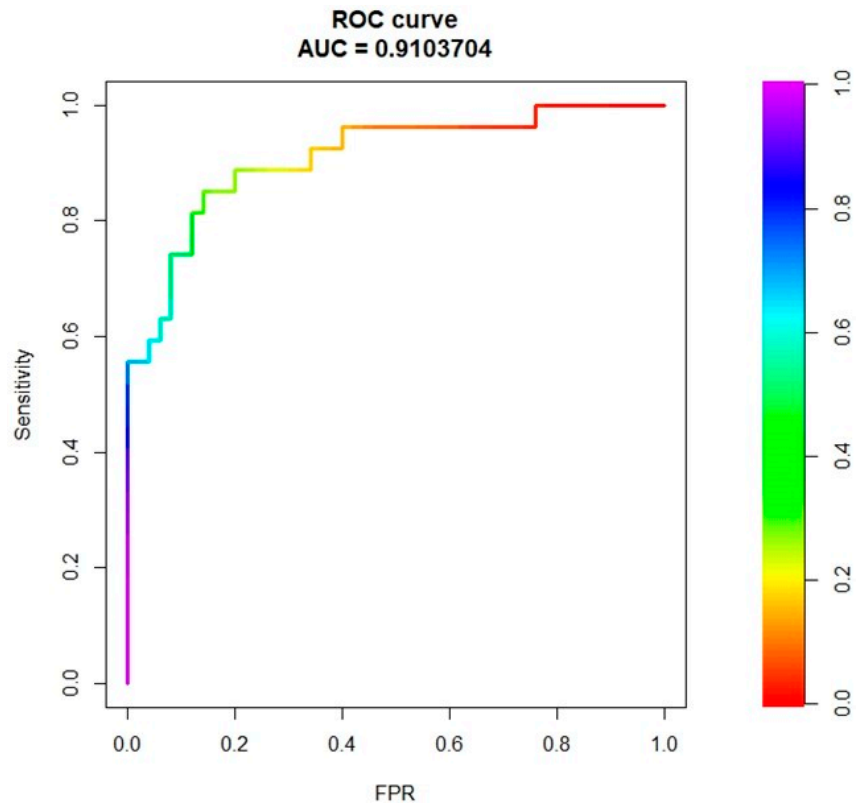

Figure 3. ROC curve analysis referring to the prediction of NRH (no vs. yes), considering clinical, laboratory, and radiomic variables for model training.

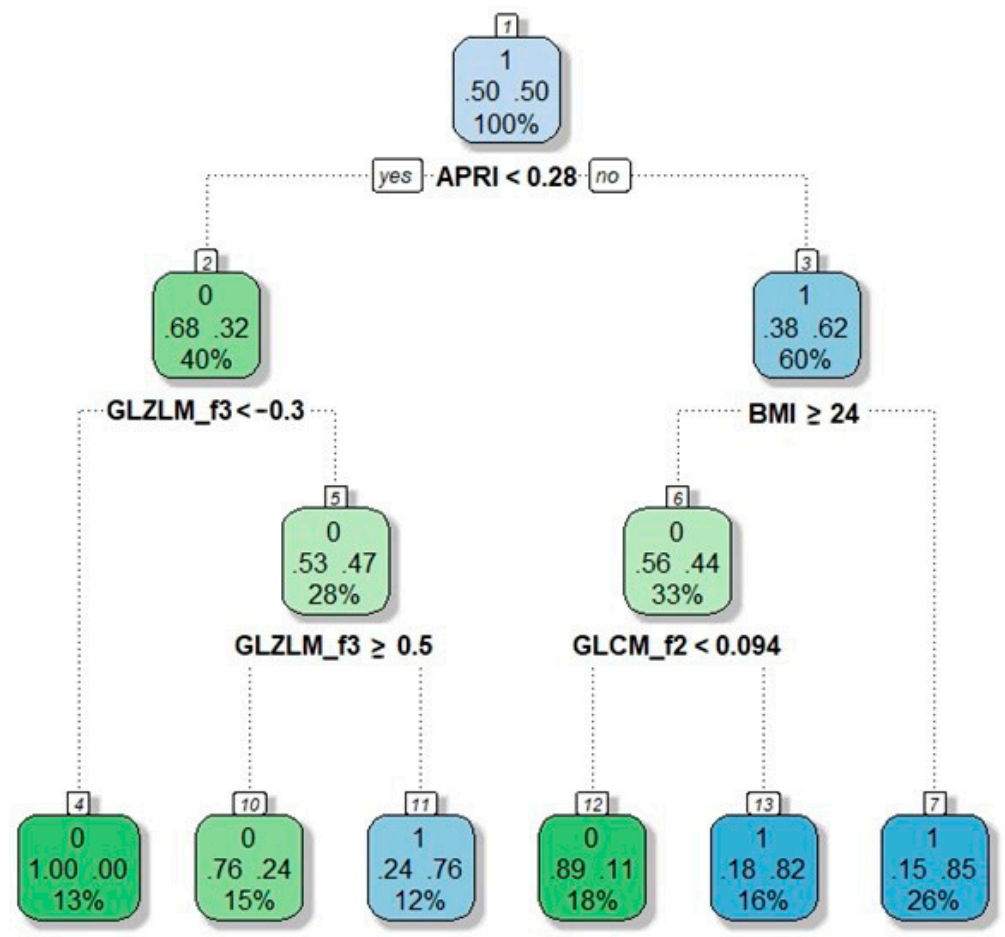

Figure 4. Decision tree for the prediction of NRH (based on model in Table 4). Nodes correspond to the decision steps. Each colored square reports: (a) the response mode class in the node, i.e., the predicted outcome of that node (presence of $\mathrm{NRH}=1$; absence of $\mathrm{NRH}=0$, the top number in the square); (b) the percentages of observations in the node belonging to the first response class (absence of NRH) and the second response class (presence of NRH) (the two central numbers in the square, summing up to 1); (c) the percentage of the total population falling into the node (the bottom number in the square). Decision rules are specified on each node.

\subsection{Predictive Model for NASH}

At the multivariate analysis, one radiomic feature was associated with NASH (Table 5): conventional_HUQ2 $(\mathrm{OR}=0.79, \mathrm{CI} 95 \%=0.66-0.94, p=0.010)$. 
Table 5. Multivariate analysis of predictors of NASH.

\begin{tabular}{ccc}
\hline Variable & OR (95\% IC) & $p$ \\
\hline CONVENTIONAL_HUQ2 & $0.79(0.66-0.94)$ & 0.010 \\
\hline GLZLM_f2 & $0.22(0.03-1.66)$ & 0.143 \\
\hline HUQ2, Hounsfield Unit Quartile 2; GLZLM_f2, Grey-Level Zone Length Matrix Fingerprint 2. &
\end{tabular}

Steatohepatitis was predicted with $91 \%$ accuracy, $86 \%$ sensitivity, and $92 \%$ specificity (AUC $=0.93$, Figure 5).

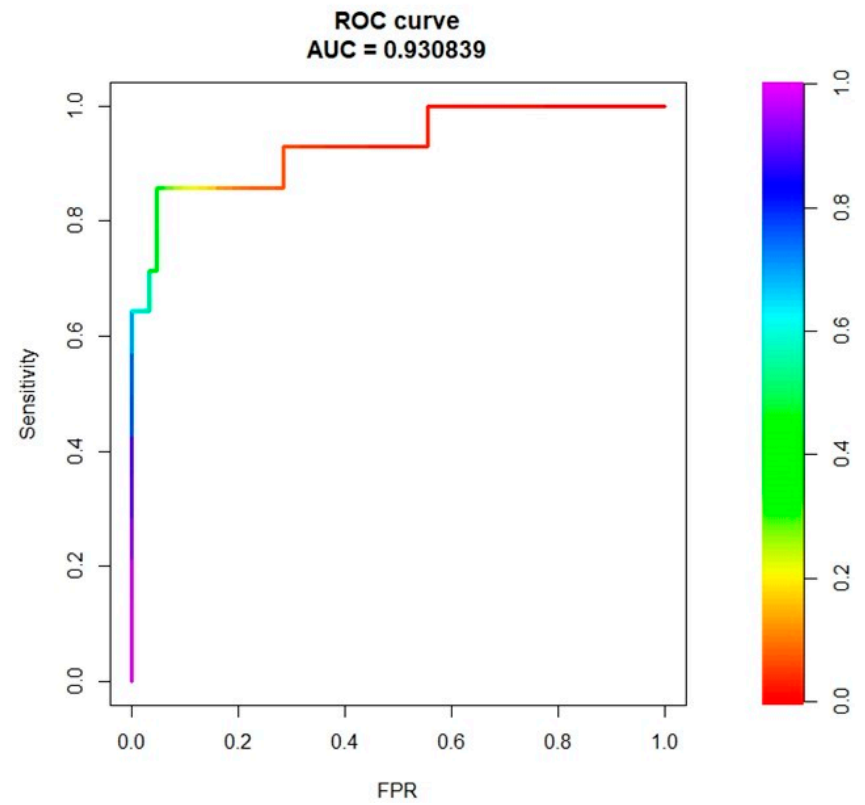

Figure 5. ROC curve analysis referring to the prediction of NASH (yes vs. no), considering clinical, laboratory, and radiomic variables for model training.

The model without radiomic features had AUC $=0.83$ (Figure S3, delta with the model including the radiomic features $=-0.10$ ). The decision tree based on the results of multivariate analysis had a single knot, i.e., conventional_HUQ2 $\geq 99$ (Figure 6).

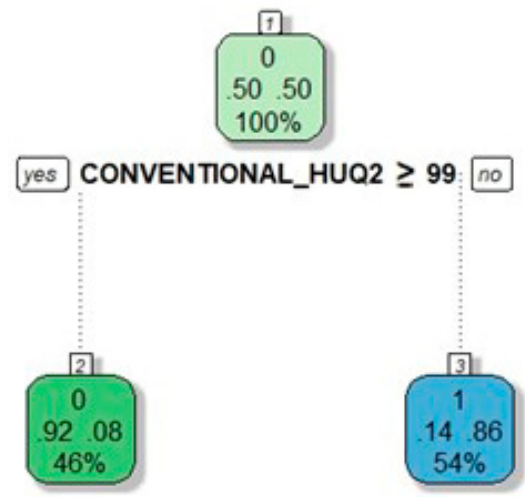

Figure 6. Decision tree for the prediction of NASH (based on model in Table 5). Nodes correspond to the decision steps. Each colored square reports: (a) the response mode class in the node, i.e., the predicted outcome of that node (presence of $\mathrm{NASH}=1$; absence of $\mathrm{NASH}=0$, the top number in the square); (b) the percentages of observations in the node belonging to the first response class (absence of NASH) and the second response class (presence of NASH) (the two central numbers in the square, summing up to 1); (c) the percentage of the total population falling into the node (the bottom number in the square). Decision rules are specified on each node. 
It achieved $86 \%$ accuracy, $93 \%$ sensitivity, and $84 \%$ specificity $(\mathrm{AUC}=0.88)$. In the validation set, the multivariate logistic regression had an average accuracy of 91\% (Std Dev 11\%).

\subsection{Contribution of Radiomic Features Extracted from the Unenhanced CT Scan}

In the same setting of 78 patients, we analyzed the performances of models considering radiomic features extracted from the unenhanced CT scans. No textural parameter was predictive of grade 2-3 sinusoidal dilatation. Considering $\mathrm{NRH}$, the following independent predictors were identified: Hist_IQR (OR 0.55, CI $=0-34-0.89, p=0.01)$, NGLDM_f2 (OR 0.16, CI = 0.04-0.067 $p=0.012)$, and GLZLM_f5 (OR 30.46 CI = 1.24-745.57 $p=0.036$ ). The model identified at the multivariate analysis had $82 \%$ accuracy, $74 \%$ sensitivity, and $86 \%$ specificity (AUC $=0.91$ ). In the validation set, the model had an average accuracy of $71 \%$ (Std Dev 12\%). Considering NASH, conventional HUQ2 (OR 0.52, CI = 0.31-0.87 $p=0.009$ ) was confirmed as independent predictor, with a $94 \%$ accuracy, $93 \%$ sensitivity and $94 \%$ specificity (AUC $=0.99$ ). In the validation set, the model had an average accuracy of $85 \%$ (Std Dev 10\%).

\section{Discussion}

An accurate non-invasive diagnosis of NASH and CALI is a relevant unmet need for clinicians. Standard imaging modalities provide a reliable diagnosis of steatosis, but not of NASH and CALI $[25,26]$. Some radiological signs of sinusoidal dilatation and NRH have been depicted, such as liver parenchyma heterogeneity and focal hyperintensities at magnetic resonance imaging, liver atrophy after chemotherapy at CT scan, and splenomegaly, but their assessment is not standardized [25,49-52]. Also a percutaneous liver biopsy has low reliability in identifying liver injuries other than steatosis because of their heterogeneous distribution and the small amount of sampled tissue available [27]. To date, CALI prediction relies on patients' history, i.e., chemotherapy regimen and the number of administered cycles, and on some liver function tests, such as APRI score or ICG test, even if the results of these tools are misleading in up to one-third of patients [10,11,16,19,22-24].

Recently, image mining and analysis have presented new perspectives. During the past decades, several approaches - statistical, geometrical, structural, and model-based methods to transform-based techniques - have been explored to extract quantitative information from images and develop potential non-invasive biomarkers to detect and characterize diseases [53]. Above all, the use of grey level co-occurrence and higher-order matrices has rooted in clinical research as texture descriptors, although their adoption has generally turned into automatic feature extraction tools, namely radiomics [54]. Radiomics involve the definition of mathematical features able to capture data on the grey-scale patterns, interpixel relationships, shape, and spectral properties within regions of interest on radiological images [55]. This technique allows researchers to access standardized texture information about images and to carry out informed inference, aiding traditional clinical investigations. To date, radiomics effectively predict biological characteristics and outcomes of several diseases [28,56,57]. In CLM patients, evidence is preliminary, but texture analysis not only improves prediction of survival compared to standard prognosticators but also provides earlier and more accurate prediction of response to chemotherapy than RECIST criteria [29]. Radiomics also accurately identifies fibrosis when applied to liver parenchyma analysis [30-33]. However, no study analyzed the association of textural features with CALI.

Radiomics are expected to detect CALI-related tissue heterogeneity and alterations, as confirmed by the present analysis. Considering sinusoidal dilatation and NRH, radiomic signatures improved the diagnosis of liver injuries achieved by standard clinical and laboratory parameters: the inclusion of radiomic predictors in the multivariate model increased the AUC by 0.10 for sinusoidal dilatation (overall AUC 0.87) and by 0.06 for NRH (AUC 0.91). Soubrane et al. reported similar performances of the APRI score for the prediction of sinusoidal dilatation (AUC 0.85) [19], but such good results were not confirmed by other series. The present study demonstrated that radiomic features inte- 
grate the "traditional" predictors, i.e., APRI score, anti-VEGF therapies, and chemotherapy duration $[10,12,16,19]$. The performances of the combined model were promising for sinusoidal dilatation ( $64 \%$ sensitivity, $82 \%$ accuracy), and very good for NRH ( $81 \%$ and $85 \%$, respectively). The adoption of a decision tree further improved the diagnosis of sinusoidal dilatation ( $92 \%$ sensitivity), better exploiting potential nonlinear associations of the radiomic predictors with the outcome. Split-oriented decision steps in tree-based models not only optimized results but also provided an easy-to-handle tool that substantiates the clinical applicability of radiomics. Radiomic features associated with sinusoidal dilatation and NRH (derived from NGLDM, GLRLM, GLZLM, and GLCM matrices) catch the tissue heterogeneity, expressed as grey-level variability between one voxel and its neighbors in the three-dimensions and the homogeneity of runs of voxels in two or three dimensions. This is in line with pathology data that depict irregular sinusoidal congestion and nodular area, and with data of magnetic resonance imaging that show some irregular parenchymal enhancement $[8,49]$.

Significant data were also obtained for NASH. The Hounsfield Q2 values (HUQ2, i.e., the Hounsfield value of the second quartile, median value) led to a highly reliable diagnosis of steatohepatitis ( $86 \%$ sensitivity, $92 \%$ specificity). The addition of radiomic features to standard clinical predictors increased the AUC by 0.10 with the identified cut-off value associated with extremely high performances (93\% sensitivity, 86\% accuracy). HUQ2 measures the intensity of tissue signal within a certain attenuation range that is coherent with the presence of steatosis, the most relevant component of NASH [26]. This parameter is more a statistical measure rather than a higher order textural feature. Nonetheless, the present analysis provided a cut-off value of HUQ2 that made it a usable tool for NASH diagnosis. We obtained the same results and performances (HUQ2, accuracy 94\%) when the textural features extracted from unenhanced CT scans were considered, suggesting that radiomics may adequately capture these tissue characteristics even without the need for contrast enhancement.

The present study also proposed a virtual biopsy of the non-tumoral liver, an easyto-collect standardized VOI with a large tissue sample $(25 \times 10 \mathrm{~mm}$, approximatively $2 \mathrm{~cm}^{3}$ of liver tissue), much larger than actual liver biopsies and enough to catch the heterogeneous distribution of CALI. It is true that a radiomic analysis of the entire liver could be more exhaustive but this would require a much more complex segmentation with a time-consuming exclusion of intrahepatic vessels and tumors and significantly greater computational power. In the future, the implementation of AI-driven segmentation protocols and the advent of quantum computing will probably overcome these limitations. The present virtual biopsy is highly reproducible and the adoption of software with automatic extraction of radiomic features ( $\mathrm{Life}^{\circledR}$ ) increases the potential diffusion of this approach, even if the interpretability and explainability of radiomic data are still debated.

A reliable assessment of NASH and CALI could have a consistent impact on clinical practice. Sinusoidal dilatation, NRH, and steatohepatitis are associated with an increased risk of intraoperative bleeding, postoperative liver failure, and mortality. The surgical strategy could be adapted to the characteristics of the non-tumoral liver [21]. Higher cut-off volume values of the future liver remnant could be pursued in the presence of CALI or $\mathrm{NASH}$, leading to extended indications to preoperative portal vein occlusion [58]. The presence of portal hypertension should be excluded in patients with NASH and NRH [10,15,59]. Further clinical applications of the proposed virtual biopsy can be anticipated. CALI have some correlations with the effectiveness of chemotherapy (the higher the grade of sinusoidal injury, the lower the pathological response rate) and their identification is essential to further understand this association $[11,60]$. An accurate diagnosis of CALI is needed in case of CLM recurrence to evaluate the liver tolerance to new chemotherapy lines and repeat surgery [61]. Steatosis and NASH have an increasing incidence in Western countries because of their close relationship with obesity and metabolic syndrome and may lead to liver dysfunction and tumors in the long term $[14,15,62]$. The virtual biopsy could be helpful to monitor liver injuries and identify patients at risk for complications. Similarly, 
some chronic medications may lead to steatohepatitis [46]. Steatosis and NASH have shown some reversibility with lifestyle modifications, correction of metabolic disorders, and bariatric surgery $[14,63,64]$, but non-invasive diagnosis of CALI is mandatory to verify the effectiveness of any treatment.

The present analysis has some limitations to address. First, it is an exploratory retrospective study with a limited number of patients. Data are preliminary and require an external validation but it is important to note that they are based on some robust foundations: CALI had a standardized and prospective evaluation, patients were treated over a short two-year period with homogeneous schedules, standard predictors of CALI were confirmed together with the new contribution of radiomic signatures, and internal validation provided encouraging confirmation of good performances. A second limitation is that some predictors of CALI were not tested, such as the ICG test or LiMax test, but they are not standard in clinical practice and are expected to give a contribution similar to the APRI score. A third is related to the reproducibility of data that could be reduced by the heterogeneity of imaging techniques among institutions, even if the CT scan is the most standardized imaging modality. Finally, the usability of radiomic features remains an issue. Our explorative analysis provided intriguing data, but we are still far from accomplishing a real clinical application of radiomics, which remains the challenge of research in the near future. Radiomics does indeed suffer from closed-source nature, unharmonized acquisition settings, discordant reconstruction parameters, lack of interpretability, redundancy, and methodological bias [54,65,66]. A wide and active research area is growing around grey-level quantization and pre-processing, aiming at informative rather than descriptive statistics from images. Such studies could open new perspectives in clinical applications of medical imaging analysis.

\section{Conclusions}

In conclusion, it was observed that a radiomic signature based on the texture analysis of liver parenchyma might improve diagnosis of sinusoidal dilatation, NRH, and steatohepatitis. Although the application of radiomics to clinical practice is still to be accomplished, our preliminary data can provide a basis for an innovative precision medicine approach to patients at risk for liver injuries.

Supplementary Materials: The following are available online at https: / www.mdpi.com/article / 10.3390/cancers13123077/s1, Figure S1: ROC curve analysis of the clinical and laboratory model for the prediction of grade 2-3 sinusoidal dilatation, Figure S2: ROC curve analysis of the clinical and laboratory model for the prediction of NRH, Figure S3: ROC curve analysis of the clinical and laboratory model for the prediction of NASH, Table S1: Chemotherapy-related liver injuries, Table S2: Association between CALI and operative outcomes. References $[67,68]$ are referred to in Supplementary Materials.

Author Contributions: Conceptualization: L.V., G.C., F.I., A.C., L.S.P., L.B., A.A. and G.T.; methodology: L.V., F.I., G.C., L.C. and C.M.; resources: G.T., L.V., G.C., F.I., A.C., L.B., L.S.P. and A.A.; data collection: G.C., F.F., L.d.T., L.C., C.M. and M.S.; data analysis and results interpretation: L.V., G.C., F.I., L.C., C.M., M.S., A.C., L.d.T. and G.T.; writing-original draft preparation: G.C., L.C., C.M. and F.F.; writing—review and editing: all authors; supervision: L.V., G.T., F.I., A.C., L.S.P., L.B., A.A. and L.d.T. All authors have read and agreed to the published version of the manuscript.

Funding: This research was founded by the AIRC Foundation for Cancer Research in Italy (Fondazione AIRC per la Ricerca sul Cancro, AIRC), grant number 2019-23822 to L.V.

Institutional Review Board Statement: The study was conducted according to the guidelines of the Declaration of Helsinki and approved by the Institutional Review Board (or Ethics Committee) of Humanitas Clinical and Research Hospital IRCCS (protocol code 1033, last amendment approved 23 February 2021).

Informed Consent Statement: Patient's consent was waived because of the study design (retrospective). 
Data Availability Statement: The data presented in this study are available on request from the corresponding author. The data are not publicly available due to privacy restrictions.

Acknowledgments: The authors thank Patricia Taylor for editing a draft of the manuscript.

Conflicts of Interest: A.C.: COI: no COIs pertinent to this work; COIs outside this work: received speaker's honoraria from the following companies: Advanced Accelerator Applications, General Electric Healthcare, Sirtex Medical Europe, AmGen Europe, travel grants form General Electric Healthcare and Sirtex Medical Europe; he is a member of Blue Earth Diagnostics' and Advanced Accelerator Applications' advisory boards and received scientific support, in terms of a three-year Ph.D. fellowship, from the Sanofi Genzyme. F.F.: COI: no COIs pertinent to this work; COIs outside this work acts as a consultant for the MSD Sharp \& Dohme GmbH (LLC). All remaining authors have declared no conflicts of interest.

\section{References}

1. Van Cutsem, E.; Cervantes, A.; Adam, R.; Sobrero, A.; Van Krieken, J.H.; Aderka, D.; Aranda Aguilar, E.; Bardelli, A.; Benson, A.; Bodoky, G.; et al. ESMO consensus guidelines for the management of patients with metastatic colorectal cancer. Ann. Oncol. 2016, 27, 1386-1422. [CrossRef]

2. Viganò, L.; Torzilli, G.; Cimino, M.; Imai, K.; Vibert, E.; Donadon, M.; Castaing, D.; Adam, R. Drop-out between the two liver resections of two-stage hepatectomy. Patient selection or loss of chance? Eur. J. Surg. Oncol. 2016, 42, 1385-1393. [CrossRef]

3. Nordlinger, B.; Sorbye, H.; Glimelius, B.; Poston, G.J.; Schlag, P.M.; Rougier, P.; Bechstein, W.O.; Primrose, J.N.; Walpole, E.T.; Finch-Jones, M.; et al. Perioperative FOLFOX4 chemotherapy and surgery versus surgery alone for resectable liver metastases from colorectal cancer (EORTC 40983): Long-term results of a randomised, controlled, phase 3 trial. Lancet Oncol. 2013, 14, 1208-1215. [CrossRef]

4. Adam, R.; Pascal, G.; Castaing, D.; Azoulay, D.; Delvart, V.; Paule, B.; Levi, F.; Bismuth, H. Tumor progression while on chemotherapy: A contraindication to liver resection for multiple colorectal metastases? Ann. Surg. 2004, 240, 1052-1064. [CrossRef] [PubMed]

5. Viganó, L.; Capussotti, L.; Barroso, E.; Nuzzo, G.; Laurent, C.; Ijzermans, J.N.M.; Gigot, J.F.; Figueras, J.; Gruenberger, T.; Mirza, D.F.; et al. Progression while receiving preoperative chemotherapy should not be an absolute contraindication to liver resection for colorectal metastases. Ann. Surg. Oncol. 2012, 19, 2786-2796. [CrossRef] [PubMed]

6. Capussotti, L.; Vigano, L.; Ferrero, A.; Lo Tesoriere, R.; Ribero, D.; Polastri, R. Timing of resection of liver metastases synchronous to colorectal tumor: Proposal of prognosis-based decisional model. Ann. Surg. Oncol. 2007, 14, 1143-1150. [CrossRef]

7. Adam, R.; Wicherts, D.A.; De Haas, R.; Ciacio, O.; Levi, F.; Paule, B.; Ducreux, M.; Azoulay, D.; Bismuth, H.; Castaing, D. Patients with initially unresectable colorectal liver metastases: Is there a possibility of cure? J. Clin. Oncol. 2009, 27, 1829-1835. [CrossRef]

8. Rubbia-Brandt, L.; Audard, V.; Sartoretti, P.; Roth, A.D.; Brezault, C.; Le Charpentier, M.; Dousset, B.; Morel, P.; Soubrane, O.; Chaussade, S.; et al. Severe hepatic sinusoidal obstruction associated with oxaliplatin-based chemotherapy in patients with metastatic colorectal cancer. Ann. Oncol. 2004, 15, 460-466. [CrossRef] [PubMed]

9. Vauthey, J.N.; Pawlik, T.M.; Ribero, D.; Wu, T.T.; Zorzi, D.; Hoff, P.M.; Xiong, H.Q.; Eng, C.; Lauwers, G.Y.; Mino-Kenudson, M.; et al. Chemotherapy regimen predicts steatohepatitis and an increase in 90-day mortality after surgery for hepatic colorectal metastases. J. Clin. Oncol. 2006, 24, 2065-2072. [CrossRef]

10. Viganò, L.; Rubbia-Brandt, L.; De Rosa, G.; Majno, P.; Langella, S.; Toso, C.; Mentha, G.; Capussotti, L. Nodular regenerative hyperplasia in patients undergoing liver resection for colorectal metastases after chemotherapy: Risk factors, preoperative assessment and clinical impact. Ann. Surg. Oncol. 2015, 22, 4149-4157. [CrossRef]

11. Viganò, L.; Capussotti, L.; De Rosa, G.; De Saussure, W.O.; Mentha, G.; Rubbia-Brandt, L. Liver resection for colorectal metastases after chemotherapy: Impact of chemotherapy-related liver injuries, pathological tumor response, and micrometastases on long-term survival. Ann. Surg. 2013, 258, 731-742. [CrossRef]

12. Rubbia-Brandt, L.; Lauwers, G.Y.; Wang, H.; Majno, P.E.; Tanabe, K.; Zhu, A.; Brezault, C.; Soubrane, O.; Abdalla, E.K.; Vauthey, J.N.; et al. Sinusoidal obstruction syndrome and nodular regenerative hyperplasia are frequent oxaliplatin-associated liver lesions and partially prevented by bevacizumab in patients with hepatic colorectal metastasis. Histopathology 2010, 56, 430-439. [CrossRef]

13. Mahli, A.; Saugspier, M.; Koch, A.; Sommer, J.; Dietrich, P.; Lee, S.; Thasler, R.; Schulze-Luehrmann, J.; Luehrmann, A.; Thasler, W.E.; et al. ERK activation and autophagy impairment are central mediators of irinotecan-induced steatohepatitis. Gut 2018, 67, 746-756. [CrossRef]

14. Sheka, A.C.; Adeyi, O.; Thompson, J.; Hameed, B.; Crawford, P.A.; Ikramuddin, S. Nonalcoholic Steatohepatitis: A Review. JAMA J. Am. Med. Assoc. 2020, 323, 1175-1183. [CrossRef] [PubMed]

15. Viganò, L.; Conci, S.; Cescon, M.; Fava, C.; Capelli, P.; D’Errico, A.; Torzilli, G.; Di Tommaso, L.; Giuliante, F.; Vecchio, F.M.; et al. Liver resection for hepatocellular carcinoma in patients with metabolic syndrome: A multicenter matched analysis with HCVrelated HCC. J. Hepatol. 2015, 63, 93-101. [CrossRef] [PubMed] 
16. Nakano, H.; Oussoultzoglou, E.; Rosso, E.; Casnedi, S.; Chenard-Neu, M.P.; Dufour, P.; Bachellier, P.; Jaeck, D. Sinusoidal injury increases morbidity after major hepatectomy in patients with colorectal liver metastases receiving preoperative chemotherapy. Ann. Surg. 2008, 247, 118-124. [CrossRef]

17. De Meijer, V.E.; Kalish, B.T.; Puder, M.; IJzermans, J.N.M. Systematic review and meta-analysis of steatosis as a risk factor in major hepatic resection. Br. J. Surg. 2010, 97, 1331-1339. [CrossRef]

18. Aloia, T.; Sebagh, M.; Plasse, M.; Karam, V.; Lévi, F.; Giacchetti, S.; Azoulay, D.; Bismuth, H.; Castaing, D.; Adam, R. Liver histology and surgical outcomes after preoperative chemotherapy with fluorouracil plus oxaliplatin in colorectal cancer liver metastases. J. Clin. Oncol. 2006, 24, 4983-4990. [CrossRef] [PubMed]

19. Soubrane, O.; Brouquet, A.; Zalinski, S.; Terris, B.; Brézault, C.; Mallet, V.; Goldwasser, F.; Scatton, O. Predicting high grade lesions of sinusoidal obstruction syndrome related to oxaliplatin-based chemotherapy for colorectal liver metastases. Ann. Surg. 2010, 251, 454-460. [CrossRef] [PubMed]

20. Zhao, J.; Van Mierlo, K.M.C.; Gómez-Ramírez, J.; Kim, H.; Pilgrim, C.H.C.; Pessaux, P.; Rensen, S.S.; Van der Stok, E.P.; Schaap, F.G.; Soubrane, O.; et al. Systematic review of the influence of chemotherapy-associated liver injury on outcome after partial hepatectomy for colorectal liver metastases. Br. J. Surg. 2017, 104, 990-1002. [CrossRef]

21. Viganò, L.; Sollini, M.; Ieva, F.; Fiz, F.; Torzilli, G. Chemotherapy-associated liver injuries. Unmet needs and new insights for surgical oncologists. Ann. Surg. Oncol. 2021, 1-6. [CrossRef]

22. Takamoto, T.; Hashimoto, T.; Sano, K.; Maruyama, Y.; Inoue, K.; Ogata, S.; Takemura, T.; Kokudo, N.; Makuuchi, M. Recovery of liver function after the cessation of preoperative chemotherapy for colorectal liver metastasis. Ann. Surg. Oncol. 2010, 17, 2747-2755. [CrossRef] [PubMed]

23. Wakiya, T.; Kudo, D.; Toyoki, Y.; Ishido, K.; Kimura, N.; Narumi, S.; Kijima, H.; Hakamada, K. Evaluation of the usefulness of the indocyanine green clearance test for chemotherapy-associated liver injury in patients with colorectal cancer liver metastasis. Ann. Surg. Oncol. 2014, 21, 167-172. [CrossRef] [PubMed]

24. Lock, J.F.; Westphal, T.; Rubin, T.; Malinowski, M.; Schulz, A.; Jara, M.; Bednarsch, J.; Stockmann, M. LiMAx Test improves diagnosis of chemotherapy-associated liver injury before resection of colorectal liver metastases. Ann. Surg. Oncol. 2017, 24, 2447-2455. [CrossRef]

25. Zhang, Y.; Yan, Y.; Song, B. Noninvasive imaging diagnosis of sinusoidal obstruction syndrome: A pictorial review. Insights Imaging 2019, 10, 110. [CrossRef] [PubMed]

26. Castera, L.; Friedrich-Rust, M.; Loomba, R. Noninvasive assessment of liver disease in patients with nonalcoholic fatty liver disease. Gastroenterology 2019, 156, 1264-1281.e4. [CrossRef]

27. Viganò, L.; Ravarino, N.; Ferrero, A.; Motta, M.; Torchio, B.; Capussotti, L. Prospective evaluation of accuracy of liver biopsy findings in the identification of chemotherapy-associated liver injuries. Arch. Surg. 2012, 147, 1085-1091. [CrossRef] [PubMed]

28. Sollini, M.; Bandera, F.; Kirienko, M. Quantitative imaging biomarkers in nuclear medicine: From SUV to image mining studies. Highlights from annals of nuclear medicine 2018. Eur. J. Nucl. Med. Mol. Imaging 2019, 46, 2737-2745. [CrossRef] [PubMed]

29. Fiz, F.; Viganò, L.; Gennaro, N.; Costa, G.; La Bella, L.; Boichuk, A.; Cavinato, L.; Sollini, M.; Politi, L.S.; Chiti, A.; et al. Radiomics of liver metastases: A systematic review. Cancers 2020, 12, 2881. [CrossRef] [PubMed]

30. Lubner, M.G.; Jones, D.; Kloke, J.; Said, A.; Pickhardt, P.J. CT texture analysis of the liver for assessing hepatic fibrosis in patients with hepatitis C virus. Br. J. Radiol. 2019, 92, 20180153. [CrossRef]

31. Lubner, M.G.; Malecki, K.; Kloke, J.; Ganeshan, B.; Pickhardt, P.J. Texture analysis of the liver at MDCT for assessing hepatic fibrosis. Abdom. Radiol. 2017, 42, 2069-2078. [CrossRef]

32. Park, H.J.; Lee, S.S.; Park, B.; Yun, J.; Sung, Y.S.; Shim, W.H.; Shin, Y.M.; Kim, S.Y.; Lee, S.J.; Lee, M.G. Radiomics analysis of gadoxetic acid-enhanced MRI for staging liver fibrosis. Radiology 2019, 290, 380-387. [CrossRef]

33. Wang, K.; Lu, X.; Zhou, H.; Gao, Y.; Zheng, J.; Tong, M.; Wu, C.; Liu, C.; Huang, L.; Jiang, T.; et al. Deep learning radiomics of shear wave elastography significantly improved diagnostic performance for assessing liver fibrosis in chronic hepatitis B: A prospective multicentre study. Gut 2019, 68, 729-741. [CrossRef] [PubMed]

34. Nioche, C.; Orlhac, F.; Boughdad, S.; Reuze, S.; Goya-Outi, J.; Robert, C.; Pellot-Barakat, C.; Soussan, M.; Frouin, F.; Buvat, I. Lifex: A freeware for radiomic feature calculation in multimodality imaging to accelerate advances in the characterization of tumor heterogeneity. Cancer Res. 2018, 78, 4786-4789. [CrossRef] [PubMed]

35. Nioche, C. LifeX Sofware. Available online: www.lifexsoft.org (accessed on 10 March 2021).

36. Viganò, L.; Procopio, F.; Cimino, M.M.; Donadon, M.; Gatti, A.; Costa, G.; Del Fabbro, D.; Torzilli, G. Is tumor detachment from vascular structures equivalent to R0 resection in surgery for colorectal liver metastases? An observational cohort. Ann. Surg. Oncol. 2016, 23, 1352-1360. [CrossRef]

37. Vigano, L.; Darwish, S.S.; Rimassa, L.; Cimino, M.; Carnaghi, C.; Donadon, M.; Procopio, F.; Personeni, N.; Del Fabbro, D.; Santoro, A.; et al. Progression of colorectal liver metastases from the end of chemotherapy to resection: A new contraindication to surgery? Ann. Surg. Oncol. 2018, 25, 1676-1685. [CrossRef]

38. Torzilli, G.; Viganò, L.; Gatti, A.; Costa, G.; Cimino, M.; Procopio, F.; Donadon, M.; Del Fabbro, D. Twelve-year experience of "radical but conservative" liver surgery for colorectal metastases: Impact on surgical practice and oncologic efficacy. HPB 2017, 19, 775-784. [CrossRef] [PubMed]

39. Stevenson, H.L.; Prats, M.M.; Sasatomi, E. Chemotherapy-induced Sinusoidal Injury (CSI) score: A novel histologic assessment of chemotherapy-related hepatic sinusoidal injury in patients with colorectal liver metastasis. BMC Cancer 2017, 17. [CrossRef] 
40. Wanless, I.R. Micronodular transformation (nodular regenerative hyperplasia) of the liver: A report of 64 cases among 2500 autopsies and a new classification of benign hepatocellular nodules. Hepatology 1990, 11, 787-797. [CrossRef]

41. Kleiner, D.E.; Brunt, E.M.; Van Natta, M.; Behling, C.; Contos, M.J.; Cummings, O.W.; Ferrell, L.D.; Liu, Y.C.; Torbenson, M.S.; Unalp-Arida, A.; et al. Design and validation of a histological scoring system for nonalcoholic fatty liver disease. Hepatology 2005, 41, 1313-1321. [CrossRef] [PubMed]

42. Marchesini, G.; Day, C.P.; Dufour, J.F.; Canbay, A.; Nobili, V.; Ratziu, V.; Tilg, H.; Roden, M.; Gastaldelli, A.; Yki-Jarvinen, H.; et al. EASL-EASD-EASO Clinical Practice Guidelines for the management of non-alcoholic fatty liver disease. J. Hepatol. 2016, 64, 1388-1402. [CrossRef] [PubMed]

43. Bedossa, P.; Poynard, T. An algorithm for the grading of activity in chronic hepatitis C. Hepatology 1996, 24, 289-293. [CrossRef] [PubMed]

44. StataCorp. Stata Statistical Software: Release 16; StataCorp LLC: College Station, TX, USA, 2019.

45. R Core Team. R: A Language and Environment for Statistical Computing; R Foundation for Statistical Computing: Vienna, Austria, 2020.

46. Bethesda. Nonalcoholic fatty liver. In LiverTox: Clinical and Research Information on Drug-Induced Liver Injury; Bethesda: National Institute of Diabetes and Digestive and Kidney Diseases: Rockville Pike, MD, USA, 2012. Available online: https://www.ncbi. nlm.nih.gov/books/NBK547860/ (accessed on 4 May 2019).

47. Bethesda. Nodular regenerative hyperplasia. In LiverTox: Clinical and Research Information on Drug-Induced Liver Injury; Bethesda: National Institute of Diabetes and Digestive and Kidney Diseases: Rockville Pike, MD, USA, 2012. Available online: https: / /www.ncbi.nlm.nih.gov/books /NBK548385/ (accessed on 4 May 2019).

48. Bethesda. Sinusoidal obstruction syndrome (veno-occlusive disease. In LiverTox: Clinical and Research Information on Drug-Induced Liver Injury; Bethesda: National Institute of Diabetes and Digestive and Kidney Diseases: Rockville Pike, MD, USA, 2012. Available online: https:/ / www.ncbi.nlm.nih.gov/books/NBK548032/ (accessed on 4 May 2019).

49. Ward, J.; Guthrie, J.A.; Sheridan, M.B.; Boyes, S.; Smith, J.T.; Wilson, D.; Wyatt, J.I.; Treanor, D.; Robinson, P.J. Sinusoidal obstructive syndrome diagnosed with superparamagnetic iron oxide-enhanced magnetic resonance imaging in patients with chemotherapy-treated colorectal liver metastases. J. Clin. Oncol. 2008, 26, 4304-4310. [CrossRef] [PubMed]

50. Overman, M.J.; Maru, D.M.; Charnsangavej, C.; Loyer, E.M.; Wang, H.; Pathak, P.; Eng, C.; Hoff, P.M.; Vauthey, J.N.; Wolff, R.A.; et al. Oxaliplatin-mediated increase in spleen size as a biomarker for the development of hepatic sinusoidal injury. J. Clin. Oncol. 2010, 28, 2549-2555. [CrossRef] [PubMed]

51. Shindoh, J.; Kobayashi, Y.; Kinowaki, K.; Mise, Y.; Gonoi, W.; Yoshida, S.; Tani, K.; Matoba, S.; Kuroyanagi, H.; Hashimoto, M. Dynamic changes in normal liver parenchymal volume during chemotherapy for colorectal cancer: Liver atrophy as an alternate marker of chemotherapy-associated liver injury. Ann. Surg. Oncol. 2019, 26, 4100-4107. [CrossRef]

52. Tani, K.; Shindoh, J.; Takamoto, T.; Shibahara, J.; Nishioka, Y.; Hashimoto, T.; Sakamoto, Y.; Hasegawa, K.; Makuuchi, M.; Kokudo, N. Kinetic changes in liver parenchyma after preoperative chemotherapy for patients with colorectal liver metastases. $J$. Gastrointest. Surg. 2017, 21, 813-821. [CrossRef]

53. Tuceryan, M.; Jain, A.K. Texture analysis. In Handbook of Pattern Recognition and Computer Vision; World Scientific: Singapore, 1993; pp. 235-276.

54. Yip, S.S.F.; Aerts, H.J.W.L. Applications and limitations of radiomics. Phys. Med. Biol. 2016, 61, R150-R166. [CrossRef] [PubMed]

55. Parekh, V.S.; Jacobs, M.A. Deep learning and radiomics in precision medicine. Expert Rev. Precis. Med. Drug Dev. 2019, 4, 59-72. [CrossRef]

56. Wen, Y.L.; Leech, M. Review of the role of radiomics in tumour risk classification and prognosis of cancer. Anticancer Res. 2020, 40, 3605-3618. [CrossRef]

57. Miranda Magalhaes Santos, J.M.; Clemente Oliveira, B.; de Araujo-Filho, J.A.B.; Assuncao-Jr, A.N.; Felipe, F.A.; Carlos Tavares Rocha, C.; Horvat, J.V.; Menezes, M.R.; Horvat, N. State-of-the-art in radiomics of hepatocellular carcinoma: A review of basic principles, applications, and limitations. Abdom. Radiol. 2020, 45, 342-353. [CrossRef] [PubMed]

58. Takamoto, T.; Hashimoto, T.; Ichida, A.; Shimada, K.; Maruyama, Y.; Makuuchi, M. Surgical strategy based on indocyanine green test for chemotherapy-associated liver injury and long-term outcome in colorectal liver metastases. J. Gastrointest. Surg. 2018, 22, 1077-1088. [CrossRef] [PubMed]

59. Ryou, M.; Stylopoulos, N.; Baffy, G. Nonalcoholic fatty liver disease and portal hypertension. Explor. Med. 2020, 1, 149-169. [CrossRef] [PubMed]

60. Zhao, J.; Sawo, P.; Rensen, S.S.; Rouflart, M.M.J.; Winstanley, A.; Vreuls, C.P.H.; Verheij, J.; Van Mierlo, K.M.C.; Lodewick, T.M.; Van Woerden, V.; et al. Impact of chemotherapy-associated liver injury on tumour regression grade and survival in patients with colorectal liver metastases. HPB 2018, 20, 147-154. [CrossRef] [PubMed]

61. Vigano, L.; De Rosa, G.; Toso, C.; Andres, A.; Ferrero, A.; Roth, A.; Sperti, E.; Majno, P.; Rubbia-Brandt, L. Reversibility of chemotherapy-related liver injury. J. Hepatol. 2017, 67, 84-91. [CrossRef]

62. Williams, C.D.; Stengel, J.; Asike, M.I.; Torres, D.M.; Shaw, J.; Contreras, M.; Landt, C.L.; Harrison, S.A. Prevalence of nonalcoholic fatty liver disease and nonalcoholic steatohepatitis among a largely middle-aged population utilizing ultrasound and liver biopsy: A prospective study. Gastroenterology 2011, 140, 124-131. [CrossRef] [PubMed] 
63. Nakamuta, M.; Morizono, S.; Soejima, Y.; Yoshizumi, T.; Aishima, S.; Takasugi, S.; Yoshimitsu, K.; Enjoji, M.; Kotoh, K.; Taketomi, A.; et al. Short-term intensive treatment for donors with hepatic steatosis in living-donor liver transplantation. Transplantation 2005, 80, 608-612. [CrossRef] [PubMed]

64. Lassailly, G.; Caiazzo, R.; Ntandja-Wandji, L.-C.; Gnemmi, V.; Baud, G.; Verkindt, H.; Ningarhari, M.; Louvet, A.; Leteurtre, E.; Raverdy, V.; et al. Bariatric surgery provides long-term resolution of nonalcoholic steatohepatitis and regression of fibrosis. Gastroenterology 2020, 159, 1290-1301.e5. [CrossRef]

65. Sollini, M.; Cozzi, L.; Ninatti, G.; Antunovic, L.; Cavinato, L.; Chiti, A.; Kirienko, M. PET/CT radiomics in breast cancer: Mind the step. Methods 2020, 188, 122-132. [CrossRef]

66. Rizzo, S.; Botta, F.; Raimondi, S.; Origgi, D.; Fanciullo, C.; Morganti, A.G.; Bellomi, M. Radiomics: The facts and the challenges of image analysis. Eur. Radiol. Exp. 2018, 2, 1-8. [CrossRef]

67. Dindo, D.; Demartines, N.; Clavien, P.A. Classification of surgical complications: A new proposal with evaluation in a cohort of 6336 patients and results of a survey. Ann Surg. 2004, 240, 205-213. [CrossRef]

68. Rahbari, N.N.; Garden, O.J.; Padbury, R.; Brooke-Smith, M.; Crawford, M.; Adam, R.; Koch, M.; Makuuchi, M.; Dematteo, R.P.; Christophi, C.; et al. Posthepatectomy liver failure: A definition and grading by the International Study Group of Liver Surgery (ISGLS). Surgery 2011, 149, 713-724. [CrossRef] [PubMed] 